\title{
Atypical cases of Familial hypocalciuric hypercalcemia: Utility of genetic testing in the diagnosis.
}

Fernando García1, Guillermo Martínez de Pinillos ${ }^{1}$, Mariana Tomé², Ignacio Fernández¹, Ignacio Fernández',

Eyvee Arturo Cuéllar ${ }^{1}$, José Álvaro Romero', Juan Manuel García de Quirós'ㄹ, María Victoria Cózar ${ }^{1}$

Hospital Universitario de Valme. Sevilla ${ }^{1}$

Hospital Punta de Europa. Gibraltar ${ }^{2}$

\section{INTRODUCTION}

Familial hypocalciuric hypercalcemia $(\mathrm{FHH})$ has been classically characterized as an asymptomatic disease with:

- Mild hypercalcemia

- Hypocalciuria < 100 mg/24h

- Normal or high serum PTH concentration.

- Urine calcium/creatinine clearance ratio $(\mathrm{UCCR})<0.01$

* Generally asymptomatic

* Family history of hypercalcemia

\section{OBJECTIVE}

* The aim of our study is to assess the utility of genetic testing in patients with suspected $\mathrm{FHH}$ with atypical clinical manifestations, and the validity of classical biochemical parameters for the diagnosis.

\section{METHODS}

* A retrospective study of 7 patients with HHF confirmed by genetic testing was conducted.

* The following variables were measured: calcemia, phosphatemia, renal function, serum PTH, 25hydroxyvitamin $\mathrm{D}, 24$-hour calciuria, urine calcium/creatinine clearance ratio (UCCR) and type of mutation.

\begin{tabular}{|c|c|c|c|c|c|c|c|c|c|}
\hline & $\begin{array}{c}\text { AGE } \\
\text { (years) }\end{array}$ & $\begin{array}{l}\text { CALCEMIA } \\
\text { (mg/dl) }\end{array}$ & $\begin{array}{l}\text { PHOSPHATEMIA } \\
\text { (mg/dl) }\end{array}$ & $\begin{array}{c}\text { PTH } \\
\text { (pg/ml) }\end{array}$ & $\begin{array}{c}25 \text {-HYDROXY } \\
\text { VITAMIN D } \\
\text { (nmol/l) }\end{array}$ & $\begin{array}{l}\text { CALCIURIA } \\
\text { (MG/24H) }\end{array}$ & UCCR & MUTATION & PAROTIDECTOMY \\
\hline 1 & $61(F)$ & 10.8 & 3.48 & 17 & 110.7 & 172 & 0.012 & C.1387C> & NO \\
\hline 2 & $37(F)$ & 11.1 & 2.94 & 51.5 & 40.2 & 109.8 & 0.004 & C. $164 C>T$ & NO \\
\hline 3 & $77(\mathrm{M})$ & 11.6 & 2.78 & 106.9 & 52 & 42 & 0.004 & C.164C>T & NO \\
\hline 4 & $38(F)$ & 10.6 & 2.11 & 43 & 24.8 & 391 & 0.03 & C.164C>T & NO \\
\hline 5 & $42(\mathrm{M})$ & 11.7 & 2.74 & 72 & 40 & 82 & 0.003 & C.164C>T & YES \\
\hline 6 & $70(F)$ & 10.9 & 2.59 & 33.4 & 50.5 & 102 & 0.008 & C. $2101 \mathrm{C}>\mathrm{G}$ & YES \\
\hline \multirow[t]{3}{*}{7} & $35(\mathrm{M})$ & 11 & 2.15 & 38.9 & 89.9 & 266 & 0.007 & C. $2101 \mathrm{C}>\mathrm{G}$ & NO \\
\hline & 51.4 years \pm 16.2 & $11.1 \mathrm{mg} / \mathrm{dl} \pm 0.4$ & $2.68 \mathrm{mg} / \mathrm{dl} \pm 0.4$ & $51.8 \mathrm{pg} / \mathrm{ml} \pm 27.3$ & $58.3 \mathrm{nmol} / \mathrm{l} \pm 28.3$ & $166 \mathrm{mg} / 24 \mathrm{~h} \pm 113.6$ & $\begin{array}{l}-C C C R<0.01: 5 \\
-0.01-0.02: 1 \\
-C C C R>0.02: 1\end{array}$ & 3 types & 2 cases of 7 \\
\hline & & $\begin{array}{c}2 \text { cases above } \\
11.5 \mathrm{mg} / \mathrm{dl}\end{array}$ & & & & $\begin{array}{c}5 \text { cases above } \\
100 \mathrm{mg} / 24 \mathrm{~h}\end{array}$ & & \begin{tabular}{|} 
Mut C.2101C>G not \\
previously \\
described in the \\
literature
\end{tabular} & $\begin{array}{l}\text { Without changes in } \\
\text { calcemia after } \\
\text { surgery }\end{array}$ \\
\hline
\end{tabular}

\section{CONCLUSIONS}

* The isolated use of classical clinical parameters for the diagnosis of HFF can determine errors in the diagnosis of those patients with atypical presentations

We believe that UCCR is preferable to the absolute value of 24 -hour calciuria, as some patients show no frank hypocalciuria.

* In these patients, genetic studies can help to avoid unnecessary surgical interventions as well as excessive costs. 